\title{
Optimization of artesunate delivery by formulation in a delayed release prosopis hemicellulose matrix
}

\author{
Emmanuel O. Olorunsola ${ }^{1 *}$, Musiliu O. Adedokun ${ }^{1}$, Partap G. Bhatia ${ }^{2}$, Babajide A. Tytler ${ }^{3}$, Michael U. Adikwu ${ }^{4}$ \\ ${ }^{1}$ Department of Pharmaceutics and Pharmaceutical Technology, University of Uyo, Uyo, Nigeria. \\ ${ }^{2}$ Department of Pharmaceutics and Pharmaceutical Microbiology, Usmanu Danfodiyo University, Sokoto, Nigeria. \\ ${ }^{3}$ Department of Pharmaceutics and Pharmaceutical Microbiology, Ahmadu Bello University, Zaria, Nigeria. \\ ${ }^{4}$ University of Abuja, Abuja, Nigeria.
}

\begin{tabular}{l} 
ARTICLE INFO \\
\hline Article history: \\
Received on: $27 / 02 / 2017$ \\
Accepted on: 20/04/2017 \\
Available online: 30/05/2017 \\
\hline Key words: \\
Artesunate; delayed release; \\
optimized delivery; \\
hemicellulose; prosopis gum.
\end{tabular}

\begin{abstract}
This study was aimed at formulating artesunate in a hemicellulose - based matrix for an optimized delivery. Artesunate (ATS) tablets containing varying concentrations of prosopis gum (PRG) in the range of 1 to $4 \% \mathrm{w} / \mathrm{w}$ were formulated. Tablets containing $3 \% \mathrm{w} / \mathrm{w}$ standard acacia gum (ACG) were also formulated to serve as a control. Tablet density, tensile strength, swelling index and swelling time were determined. Drug release and permeation were also studied. There were no significant differences in tablet density and in swelling index but tensile strength and swelling time increased significantly with increase in concentration of PRG. Rate of drug release from tablets containing 3\% w/w ACG was faster than those containing same concentration of PRG. Tablets containing 4\% $\mathrm{w} / \mathrm{w}$ PRG brought forth cumulative drug release of $27.2 \%, 57.0 \%$ and $78.6 \%$ in $30 \mathrm{~min}$, $60 \mathrm{~min}$ and $120 \mathrm{~min}$ respectively. All PRG batches brought forth complete drug permeation within $180 \mathrm{~min}$. Prosopis gum at concentration of $4 \% \mathrm{w} / \mathrm{w}$ can delay the release of artesunate so that 57.0 to $78.6 \%$ of the drug is released at the gastric region while 21.4 to $43.0 \%$ is released at the intestinal region of the gastrointestinal tract for optimized delivery of the drug.
\end{abstract}

\section{INTRODUCTION}

Artemisinin and its derivatives are generally effective in treating severe and multi-drug resistant forms of Plasmodium falciparum malaria (Augustijns et al., 1996). The World Health Organization's recommendation of artemisinin - based combination therapy for malaria has led to increased and wide use of this class of antimalarial (Chen, 2014). They are rapidly absorbed with peak plasma level occurring in $1-2$ hours. They have half-lives of $1-3$ hours (Rosenthal, 2004). The major physicochemical challenge with artemisinin, the parent compound, is its poor solubility which led to the search for the derivatives with better solubility and better antimalarial efficacy.

\footnotetext{
* Corresponding Author

Emmanuel O Olorunsola, Department of Pharmaceutics and Pharmaceutical Technology, University of Uyo, Uyo, Nigeria. Email: olorunsolaeo@yahoo.com
}

Artemether (which is lipid-soluble) and artesunate (which is water-soluble) are the two most commonly used of the derivatives (Rosenthal, 2004). The metabolism of artesunate to dihydroartemisinin is strongly $\mathrm{pH}$-dependent and the drug is less stable at acidic pH (Olliaro et al., 2001). In the stomach (pH 1.2), it has a half-life of less than 1 hour while at neutral $\mathrm{pH}$, the half-life is over 7 hours (Olliaro et al., 2001). Hence, the drug is short-lived when the dissolution occurs in the stomach; and delaying the dissolution will lead to prolonged and pronounced antimalarial activity.

Enteric coating is the most common method of protecting drugs from gastric environment to ensure dissolution in the intestine (Tirpude and Puranik, 2011). However, high cost and technology are some of the challenges of coating over conventional tableting. Therefore, a search for appropriate excipient for conventional tableting that will enable delayed release of artesunate is a good alternative to enteric coating. 
Hemicellulose hydrogels had been shown to be useful for controlled drug delivery. Afzelia gum, a xyloglucan hemicellulose, was shown to be a hydrogel with potential for use as a sustained delivery excipient (Builders et al., 2009). Wheat straw hemicellulose was used for controlled delivery of acetylsalicylic acid and theophylline (Sun et al., 2013). The polymer experienced swelling at the gastric $\mathrm{pH}$ but disintegrated and dissolved at higher $\mathrm{pH}$ to release the drugs. The hydrogel protected the drugs from the acidic environment of the stomach.

Prosopis gum from Prosopis africana seed is a hemicellulose consisting of xylose, galactose, glucose and fructose as the major monosaccharide units (Attama et al., 2000) and could delay the release of artesunate from tablet when used for the drug delivery. Characterization of the gum in a previous work (Olorunsola et al., 2016) showed that the presence of prosopis gum had no noticeable effect on the melting point of artesunate as revealed in their differential scanning thermograms. However, the FTIR spectroscopy showed that the presence of the polymer caused reduction in the height of the peaks in the spectrum of artesunate; but no new peak was formed in the interactions. This study is aimed at delaying the release of artesunate by formulation in prosopis hemicellulose matrix for the purpose of optimizing the delivery of the drug.

\section{MATERIALS AND METHODS}

\section{Materials}

The materials used were: artesunate powder - ATS

(IPCA Laboratory, India), Acacia senegal gum - ACG (BDH Chemicals, Poole, England), lactose (Surechem Products Ltd., England), magnesium stearate (Riedel-De Haen, Germany), maize starch B.P (BDH Chemicals, Poole, England), talc (BDH Chemicals, Poole, England) and prosopis gum which was extracted and characterized in our previous work (Olorunsola et al., 2016).

\section{Ethical approval}

Ethical approval for experimentation involving laboratory animal was obtained from Ethics Committee of Faculty of Pharmacy, University of Uyo, Uyo, Nigeria (protocol number $\mathrm{UU} / \mathrm{PH} / 002$ ). The pig was housed in a cross-ventilated room and later sacrificed in accordance with internationally accepted laboratory animal use and the guidelines and rules for animal experimentation.

\section{Preparation of tablets}

Artesunate granules containing varying gum concentrations as matrix former $(1.0,2.0,3.0$ and $4.0 \% \mathrm{w} / \mathrm{w})$ were prepared by wet granulation. A batch containing $3 \% \mathrm{w} / \mathrm{w}$ of standard acacia gum as control was also produced. The preparations were such that $275 \mathrm{mg}$ tablet contained $50 \mathrm{mg}$ of artesunate and varying concentrations of polymer as shown in Table 1. The artesunate powder, lactose and maize starch B.P were weighed individually and dry-mixed for $5 \mathrm{~min}$ and then moistened with mucilage of the polymer. The wet mass was screened through a $2.0 \mathrm{~mm}$ sieve, dried in a hot air oven (Gallenkamp, Germany) at $60{ }^{\circ} \mathrm{C}$ for $1 \mathrm{~h}$ and screened again through a $1.0 \mathrm{~mm}$ sieve. Talc and magnesium stearate were weighed and gently blended with the dried granules over a period of $3 \mathrm{~min}$. The resulting granules were tableted at $30 \mathrm{KN}$ compaction force using a single punch (size 8.00 $\mathrm{mm}$ ) tableting machine (Erweka, Germany).

Table 1: Formula of artesunate tablets.

\begin{tabular}{lccccc}
\hline & \multicolumn{5}{c}{ B A T C H E S } \\
\hline Ingredient & ACG3 & PRG1 & PRG2 & PRG3 & PRG4 \\
\hline Artesunate powder (\%) & 18.20 & 18.20 & 18.20 & 18.20 & 18.20 \\
Maize starch B.P (\%) & 10.00 & 10.00 & 10.00 & 10.00 & 10.00 \\
Lactose (\%) & 66.80 & 68.80 & 67.80 & 66.80 & 65.80 \\
Acacia gum (\%) & 3.00 & - & - & - & - \\
Prosopis gum (\%) & - & 1.00 & 2.00 & 3.00 & 4.00 \\
Talc (\%) & 1.50 & 1.50 & 1.50 & 1.50 & 1.50 \\
Magnesium stearate (\%) & 0.50 & 0.50 & 0.50 & 0.50 & 0.50 \\
\hline
\end{tabular}

\section{Evaluation of tablets \\ Compact density}

The dimensions (diameter and thickness) of the tablets were determined using digital caliper (Z 540-1, USA) while the masses were determined using Mettler analytical balance. Compact density, CD, was calculated using equations (1) and (2).

$$
\begin{aligned}
& \mathrm{CD}=\frac{m}{\mathrm{~V}} \\
& \mathrm{~V}=\pi \mathrm{r}^{2} \mathrm{t}
\end{aligned}
$$

Where $\mathrm{m}=$ mass of compact, $\mathrm{V}=$ volume, $\mathrm{r}=$ radius and $\mathrm{t}=$ thickness of tablet.

\section{Tensile strength}

The tensile strength, $\mathrm{T}$, of tablet was determined using hardness tester (PTB 301, Pharmatest Switzerland) and by applying equation (3) as applied by Odeku et al. (2005).

$$
\mathrm{T}=2 \mathrm{~F} / \pi \mathrm{dt}
$$

Where $\mathrm{F}$ is the load needed to cause fracture, $\mathrm{d}$ is tablet's diameter and $t$ is the thickness.

\section{Swelling properties}

The swelling properties of tablets were determined using the modified form of the method described by Ngwuluka et al. (2015). Tablet was weighed and dropped in a beaker containing 50 $\mathrm{ml}$ of $0.1 \mathrm{~N} \mathrm{HCl}$. The swollen tablet was removed from the medium at $15 \mathrm{~min}$ intervals over a period of $2 \mathrm{~h}$, the medium was blotted out and the tablet was reweighed. The highest weight obtained and the last time swelling was observed were recorded. The swelling index was calculated using equation (4).

Swelling index $=\left(\mathrm{W}_{\mathrm{t}}-\mathrm{W}_{\mathrm{o}}\right) / \mathrm{W}_{\mathrm{o}}$

Where $\mathrm{W}_{\mathrm{t}}$ is the highest weight obtained which occurred at time $\mathrm{t}$; and $\mathrm{W}_{\mathrm{o}}$ is the initial weight of tablet.

\section{Dissolution characteristics}

Dissolution test was carried out using U.S.P. dissolution apparatus (Panomex Inc., India). A tablet was placed inside the dry 
basket of the apparatus and lowered inside the beaker containing $900 \mathrm{ml}$ of $0.1 \mathrm{~N}$ hydrochloric acid thermostatically maintained at $37.0 \pm 0.5{ }^{\circ} \mathrm{C}$. The apparatus was set to a rotational speed of 100 rpm for $2 \mathrm{~h}$. Samples $(10 \mathrm{ml})$ were taken at $20 \mathrm{~min}$ intervals with subsequent replacement with equal volume of the dissolution medium. Each withdrawn sample was filtered and diluted with pure dissolution medium. The absorbance of samples was taken at 216 nm (USP Medicine Compendium, 2013) using a UV spectrophotometer (UNICO Shanghai Instrument, China). A graph of cumulative percent drug released was plotted against time.

\section{Permeation characteristics}

Simulated intestinal fluid (SIF) was prepared using the method as described by Adikwu et al. (2005). The permeation study was carried out using the modified method of Sharma et al. (2013). Each segment of the pig intestine was tied at one end and filled with $5 \mathrm{ml}$ of simulated intestinal fluid $(\mathrm{pH} \mathrm{6.8).} \mathrm{The} \mathrm{tablet}$ was introduced into the donor compartment and then tied at the other end. The donor chamber was subsequently immersed into a dissolution apparatus containing $900 \mathrm{ml}$ of the receptor medium of the same composition as the donor medium. The temperature was maintained at $37 \pm 0.5{ }^{\circ} \mathrm{C}$ and the apparatus was set to operate for $6 \mathrm{~h}$.

Aliquots $(10 \mathrm{ml})$ were withdrawn at $30 \mathrm{~min}$ intervals from the dissolution medium with replacement using pure medium. Each sample was filtered and $5 \mathrm{ml}$ of the filtrate was diluted with $5 \mathrm{ml}$ of pure medium. The resulting solution was analyzed using an ultraviolet spectrophotometer (UNICO Shanghai Instrument, China) at $216 \mathrm{~nm}$. A graph of cumulative percent drug permeated was plotted against time. The time for 95\% drug permeation ( $\mathrm{t}$ 95\%) was read from the plot. Value of steady state drug flux $(\mathrm{J})$ was calculated using the equation:

$$
\mathrm{J}=\frac{d Q}{d t A}
$$

$\mathrm{dQ}$ is the change in the quantity of drug absorbed $(\mu \mathrm{g})$ through the membrane of surface area $A\left(\mathrm{~cm}^{2}\right)$ within time $\mathrm{dt}$ (min). The value of $\mathrm{dQ} / \mathrm{dt}$ was estimated from the slope of the straight line portion of graph of percent drug permeated versus time. The permeation coefficient $\left(\mathrm{K}_{\mathrm{p}}\right)$ was calculated using the equation:

$$
K p=\frac{J}{C}
$$

$\mathrm{J}$ is the drug flux and $\mathrm{C}$ is initial concentration of the drug in the donor compartment.

\section{Data analysis}

All measurements were taken in triplicates and presented as mean \pm S.E.M. Data analysis was done using one-way analysis of variance followed by Turkey-Kramer multiple comparison test using GraphPad Instat-3 software. Significance of difference was taken at $p$ - values less than 0.05. Graphical illustrations were carried out using Microsoft Excel.

\section{RESULTS AND DISCUSSION}

\section{Physical properties of tablets}

Some physical properties of the tablets are shown in Table 2. There was no significant difference in the density of tablets containing different concentrations of gum. However, the tensile strength increased with increase in concentration of prosopis gum; and the tensile strength of tablet containing PRG3 was higher than that of ACG3.

Table 2: Some physical properties of tablets $(n=3$, mean \pm S.E.M).

\begin{tabular}{ccc}
\hline Batch & $\begin{array}{c}\text { Density } \\
\left(\mathbf{g} / \mathbf{c m}^{\mathbf{3}}\right)\end{array}$ & $\begin{array}{c}\text { Tensile strength } \\
\left(\mathbf{M N} / \mathbf{m}^{\mathbf{2}}\right)\end{array}$ \\
\hline ACG3 & $1.11 \pm 0.01$ & $0.82 \pm 0.08$ \\
PRG1 & $1.09 \pm 0.01$ & $0.73 \pm 0.01$ \\
PRG2 & $1.10 \pm 0.04$ & $0.92 \pm 0.04$ \\
PRG3 & $1.10 \pm 0.01$ & $0.95 \pm 0.01$ \\
PRG4 & $1.12 \pm 0.03$ & $1.11 \pm 0.06$ \\
\hline ACG3= 3\% w/w acacia gum, PRG1 $1 \% \mathrm{w} / \mathrm{w}$ prosopis gum, PRG2 $=2 \%$
\end{tabular}
$\mathrm{w} / \mathrm{w}$ prosopis gum, PRG3 $=3 \% \mathrm{w} / \mathrm{w}$ prosopis gum, $\mathrm{PRG} 4=4 \% \mathrm{w} / \mathrm{w}$ prosopis gum.

Tablet density is an inverse measure of the volume (size) of the compact. This parameter can be influenced by both compaction factors and the physical properties of the material to be compacted (Alderborn, 2007). To minimize variation in compaction factors, compaction was carried out at $30 \mathrm{KN}$ (based on the pilot study) for all the batches. There was no significant difference in the density of tablets containing different concentration of the gums (Table 2). Hence, the concentration of the hemicellulose (prosopis gum) had no significant effect on the tablet size and density. Densification is a process of volume reduction which occurs as pressure is applied to a powder bed (Alebiowu and Itiola, 2003).

Compaction process can result in consolidation (volume reduction), elastic deformation, plastic deformation or brittle fracture (Bodga, 2002). On application of the compaction pressure of $30 \mathrm{KN}$, the extent of volume reduction was not significantly different. Hence, the polymer concentration has no significant effect on the extent of densification.

The tensile strength of the tablets increased with increased in concentration of PRG. Tensile strength depends on the amount of plastic deformation which occurs during compaction (Odeku and Itiola, 2007). Therefore, concentration of PRG contributed more to plastic deformation rather than to volume reduction as pressure was applied. Tensile strength is a reliable means of measuring tablet strength because it takes into consideration the tablet dimensions (Halenius et al., 2014).

\section{Swelling characteristics}

The swelling characteristics of tablets are shown in Table 3. Swelling was not obtained for tablet containing ACG but the tablet dissolved within $2 \mathrm{~min}$ after being introduced into the medium. Swelling index and swelling time increased with increase in the concentration of PRG.

Prosopis gum, like other hemicelluloses, is a swellable polymer (Sun et al., 2013). The proportion of the gum used in 
relation to the tablet $(1-4 \%$ w/w) was small and this could be responsible for the insignificant difference in the swelling index. However, there was a significant difference in the swelling time; and the time increased with increase in the polymer concentration. The swelling time was taken as the last time swelling was observed. After the swelling time, the weight of the tablet continued to decrease until the tablet finally dissolved.

Table 3: Swelling characteristics of tablets $(n=3$, mean \pm S.E.M).

\begin{tabular}{ccc}
\hline Batch & Swelling index & $\begin{array}{c}\text { Swelling time } \\
(\mathbf{m i n})\end{array}$ \\
\hline ACG3 & - & - \\
PRG1 & $1.13 \pm 0.02$ & $20.00 \pm 5.00$ \\
PRG2 & $1.17 \pm 0.03$ & $55.00 \pm 5.00$ \\
PRG3 & $1.18 \pm 0.03$ & $75.00 \pm 0.00$ \\
PRG4 & $1.25 \pm 0.04$ & $85.00 \pm 5.00$ \\
\hline
\end{tabular}

$\mathrm{ACG} 3=3 \% \mathrm{w} / \mathrm{w}$ acacia gum, $\mathrm{PRG} 1=1 \% \mathrm{w} / \mathrm{w}$ prosopis gum, $\mathrm{PRG} 2=2 \%$ $\mathrm{w} / \mathrm{w}$ prosopis gum, PRG3 $=3 \% \mathrm{w} / \mathrm{w}$ prosopis gum, PRG4=4\% w/w prosopis gum.

\section{Drug release profile}

The dissolution profiles of tablets are shown in Figurr 1. Tablets containing 3\% w $/ \mathrm{w}$ ACG brought forth drug release of $75 \%$ within $30 \mathrm{~min}$ and complete drug release within $1 \mathrm{~h}$. There was $90.7 \%, 82.3 \%, 66.5 \%$ and $57.0 \%$ cumulative drug release in $1 \mathrm{~h}$ from tablets containing PRG1, PRG2, PRG3 and PRG4 respectively. Also, there was complete drug release in $2 \mathrm{~h}$ from tablets containing PRG1 and PRG2; and $85.7 \%$ and $78.6 \%$ within same period from PRG3 and PRG4 respectively.

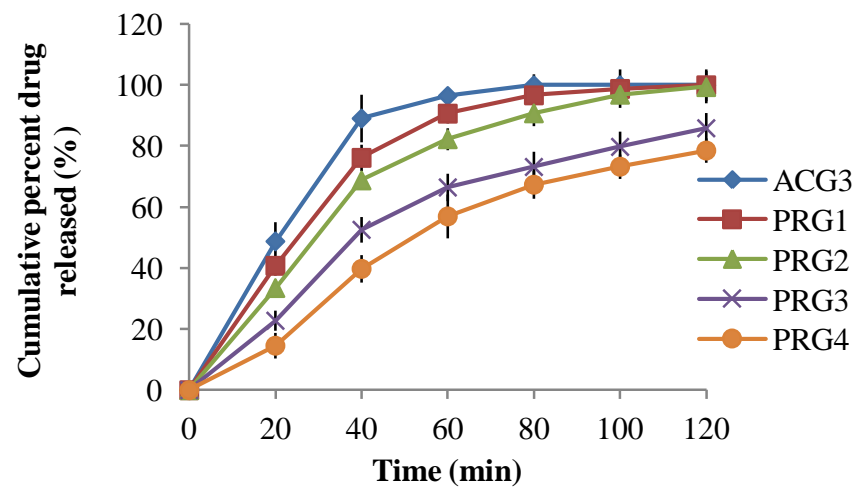

Fig. 1: Dissolution profile of artesunate tablets containing different gum concentrations.

Acacia gum is only suitable for immediate release formulation as it gave complete drug release within $1 \mathrm{~h}$ (Figure 1). The gastric residence time (GRT) in normal individuals is 5 min to $2 \mathrm{~h}$ (Ashford, 2007). About 79\% drug release was obtained from formulation PRG4 at $2 \mathrm{~h}$ (upper limit of GRT) and 57\% drug release in $60 \mathrm{~min}$ (the average GRT). Therefore, 57\% drug release in the gastric region and $43 \%$ release in the intestinal region are obtainable from PRG4 in an average individual. There is a need for the use of moderate concentration of PRG as $4 \%$ w/w to prevent excessive delay of onset of action. Since artesunate has a prolonged half-life at higher $\mathrm{pH}$ (Tirpude and Puranik, 2011), the antimalarial activity of the drug will be prolonged when substantial amount of the drug is released in the intestine.

\section{Permeation profile}

The graph of cumulative percent drug permeated versus time of permeation is shown in Figure 2 while the permeability data are shown in Table 4. The steady state drug flux was reached in $30 \mathrm{~min}$ for ACG3 and $60 \mathrm{~min}$ for PRG1, PRG2, PRG3 and PRG4. Cumulative percent drug permeated in $60 \mathrm{~min}$ decreased with increase in concentration of PRG but the steady state drug flux increased with increase in concentration of PRG. The time for 95\% drug permeated for tablets containing PRG was not significantly different.

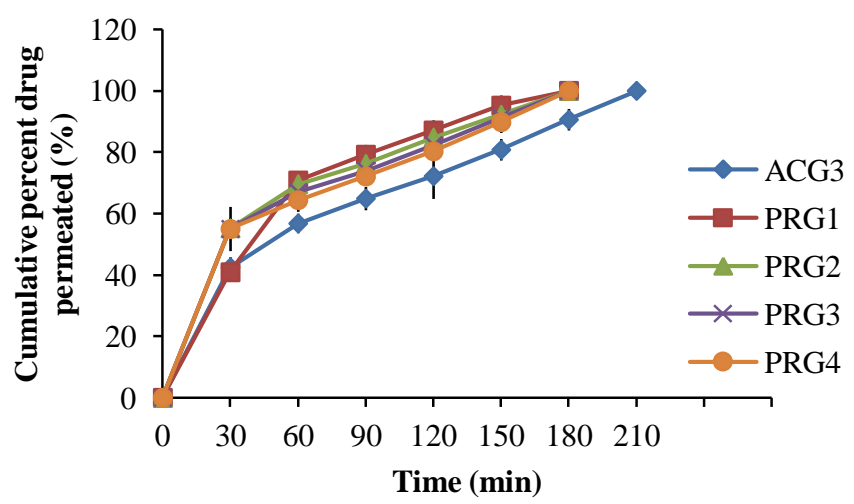

Fig. 2: Permeation profile of artesunate tablets containing different gum concentrations.

Table 4: Permeability data of tablet formulations $(n=3$, mean \pm S.E.M).

\begin{tabular}{lccc}
\hline Batch & $\begin{array}{c}\text { Drug flux } \\
\left(\boldsymbol{\mu g} / \mathbf{c m}^{\mathbf{2}} \mathbf{. s}\right)\end{array}$ & $\begin{array}{c}\text { Permeation } \\
\mathbf{c o e f f i c i e n t} \\
\mathbf{x} \mathbf{1 0}^{-\mathbf{6}}(\mathbf{c m} / \mathbf{s})\end{array}$ & $\begin{array}{c}\text { Time for 95\% } \\
\text { permeation } \\
(\mathbf{m i n})\end{array}$ \\
\hline ACG3 & $0.17 \pm 0.03$ & $16.65 \pm 3.11$ & $195.33 \pm 6.76$ \\
PRG1 & $0.14 \pm 0.01$ & $14.41 \pm 1.05$ & $154.00 \pm 7.56$ \\
PRG2 & $0.15 \pm 0.03$ & $15.19 \pm 3.11$ & $160.67 \pm 5.00$ \\
PRG3 & $0.19 \pm 0.01$ & $18.72 \pm 0.68$ & $168.67 \pm 7.34$ \\
PRG4 & $0.22 \pm 0.04$ & $22.03 \pm 4.23$ & $170.33 \pm 5.34$ \\
\hline ACG3= 3\% w/w acacia gum, PRG1=1\% w/w prosopis gum, PRG2=2\% \\
w/w prosopis gum, PRG3=3\% w/w prosopis gum, PRG4=4\% w/w prosopis \\
gum.
\end{tabular}

The steady state drug flux was reached earlier for tablet containing ACG. The delayed release and delayed steady state drug flux from prosopis gum matrices can be linked to the high binding strength of the gum and its hemicellulosic nature (Attama et al., 2000). However, the permeation coefficient at steady state increased with increase in concentration of prosopis gum. Hemicelluloses experience more of swelling at gastric $\mathrm{pH}$ but disintegrate and dissolve at higher $\mathrm{pH}$ to release the incorporated drugs (Sun et al., 2013). The high bioadhesive strength of prosopis gum (Attama et al., 2000) was found to be favorable for permeation enhancement for already released drug. The increase in time for $95 \%$ drug permeation despite the increase in permeation coefficient (at steady state) can be linked to the delay in reaching the steady state as the concentration of the polymer was increased.

Even though the steady state drug flux was delayed when the drug was formulated in matrices of PRG, the time for 95\% drug permeation was shorter compared to formulation with ACG (Figure 2). According to Suputtamongkol et al. (2001), artesunate has $\mathrm{t}_{\max }$ of $90 \mathrm{~min}$ achieving complete absorption at about 180 
min. Therefore, the eventual time of drug permeation was not adversely affected by formulation in matrix of prosopis gum. Delaying the release of the drug by formulation in this hemicellulose matrix is effective for optimizing the delivery since a substantial amount is released at the later part of GRT and in the intestine. The half-life of artesunate increases by up to seven folds between the gastric $\mathrm{pH}$ and intestinal $\mathrm{pH}$ (Olliaro et al., 2001).

Formulation of artesunate in a hemicellulose matrix as a means of delaying the release of the incorporated drug has some advantages over enteric coating. The process of tableting is simpler, cheaper and less equipment is involved. Unlike in coating where the polymer is used as outer coat for the tablet, the polymer is simply mixed or granulated with other excipients before tableting in matrix formation. Also, the onset of action of drug formulated in hemicellulose matrix is not excessively delayed since part of the drug is released in the stomach while the remaining part is released in the intestine. One major challenge with polymers of natural origin is the batch to batch variation in quality. Factors that could be responsible for this variation include the geographical source, species variation and processing variables such as method of extraction and type of solvent used. Batch to batch variation has a significant effect on the performance of these polymers. Therefore, care should be taken in obtaining polymer of good quality for use in drug delivery. One of the reliable ways of detecting batch to batch variation of a polymer is by rheological evaluation of a specific concentration of dispersions of different batches (Mancini et al., 1996). This method can be used to ensure the quality of prosopis gum.

\section{CONCLUSION}

Rate of drug release from a tablet containing acacia gum is faster than that of a tablet containing same concentration of prosopis gum. All the batches containing prosopis gum can achieve complete drug permeation within $180 \mathrm{~min}$. The gum, at a concentration of $4 \% \mathrm{w} / \mathrm{w}$ can delay the release of artesunate such that 57.0 to $78.6 \%$ of the drug is released at the gastric region while 21.4 to $43.0 \%$ is released at the intestinal region where the drug has longer half-life. Therefore, the gum at this concentration can be used for optimization of the delivery of the artesunate.

\section{ACKNOWLEDGEMENT}

Financial support and sponsorship: The authors hereby appreciate the management of University of Uyo, Uyo, Nigeria for the grant (number UU/PF/10460/vol.1/30) given to Emmanuel O. Olorunsola to undertake this research.

Conflict of Interests: There are no conflicts of interest.

\section{REFERENCES}

Adikwu MU, Nnamani PO, Attama AA. Evaluation of snail mucin as bioadhesive agent for the delivery of chlorpropamide. BioResearch, 2005; 3(2): 75 - 85 .

Alderborn G. 2007. Tablet and compaction. In: Aulton ME, ed. The Design and Manufacture of Medicine. Hungary: Churchill Livingstone Elsevier 441 - 482.
Alebiowu AG, Itiola OA. Effect of starches on mechanical properties of paracetamol formulation. Acta Pharm, 2003; 53: 231 -232.

Ashford M. 2007. Gastrointestinal tract- physiology and absorption. In: Aulton ME, ed. The Design and Manufacture of Medicine. Hungary: Churchill Livingstone Elsevier 270 - 285.

Attama AA, Adikwu MU, Okoli N. Studies in bioadhesive granules 1: Granules formulated with Prosopis africana gum. Chem Pharm Bull, 2000; 48(5): 734 - 737.

Augustijns P, D'Hulst A, Van Daele J, Kinget R. Transport of artemisinin and sodium artesunate in Caco-2 intestinal epithelia cells. $J$ Pharm Sci, 1996; 85(6): 577-579.

Bodga MJ. 2002. Tablet compression: Machine theory, design and process troubleshooting. In: Swarbrick J, Boylan J, eds. Encyclopedia of Pharmaceutical Technology. U.S.A.: Marcel Dekker Inc. 2669 - 2688.

Builders PF, Chukwu C, Obidike I, Builders MI, Attama AA, Adikwu MU. A novel xyloglucan gum from seeds of Afzelia africana Se. Pers.: Some functional and physicochemical properties. Int $J$ Green Pharm, 2009; 3(2): 112 - 118.

Chen C. Development of antimalarial drugs and their application in China: A historical review. Inf Dis Pov, 2014; 3(9): 3-9.

Halenius A, Lakio S, Antikainen O, Hatara J, Yliruus J. Fast tablet tensile strength prediction based on non-invasive analytics. AAPS PharmSciTech, 2014; 15(3): 781- 791.

Mancini M, Moresi M, Sappino F. Rheological behaviour of aqueous dispersion of algal sodium alginates. J Food Eng, 1996; 28: 283 295.

Ngwuluka NC, Nep EI, Ochekpe NA, Odumosu PO, Olorunfemi PO. Eudagrit 100 and polysaccharide polymer blends as matrices for modified-release drug delivery II: Swelling and release studies. Trop J Pharm Res, 2015; 14(12): 2163-2170.

Odeku OA, Itiola OA. Compaction properties of three types of Starch. Iran J Pharm Res, 2007; 6(1): 17-23.

Odeku OA, Awe OO, Popoola B, Odeniyi MA, Itiola OA. Compression and mechanical properties of tablet formulations containing corn, sweet potato and cocoyam starches as binders. Pharm Technol, 2005; 29: 82-90.

Olliaro PL, Nair NK, Sathasivan K, Mansor SM, Navaratnam $\mathrm{V}$. Pharmacokinetics of artesunate after single oral administration to rats Biomed Central Pharmacol, 2001; 1(12): 1-12.

Olorunsola EO, Bhatia PG, Tytler BA, Adikwu MU. Compatibility study of cashew and prosopis gums with some artemisinin derivatives. Nig J Pharm, 2016; 50(2): 35-53.

Rosenthal PJ. 2004. Antiprotozoal drugs. In: Katzung BG, ed. Basic and Clinical Pharmacology. Singapore: The McGraw-Hill Companies Inc. $864-885$.

Sharma N, Kulkarni GT, Sharma A. Development of novel Abelmoschus esculentus (Okra) gel for nasal delivery of rizatriptan benzoate. Trop J Pharm Res, 2013; 12(2): 149 - 153.

Sun XF, Wang HH, Jing ZX, Mohanathas R. Hemicellulosebased $\mathrm{pH}$-sensitive and biodegradable hydrogel for controlled drug delivery. Carbohydrate Polym, 2013; 92(2): 1357-1366.

Suputtamongkol Y, Newton PN, Angus B, Teja-Isavadharm P, Keeratithakul D, Rasameesoraj M, Pukrittayakamee S, White NJ. A comparison of oral artesunate and artemether antimalarial bioactivities in acute falciparum malaria. Brit J Cli Pharmacol, 2001; 52(6): 655 - 661.

Tirpude RN, Puranik PK. Rabeprazole sodium delayed-release multiparticulates: Effect of enteric coating layers on product performance. J Adv Pharm Technol Res, 2011; 2(3): 184-191.

United States Pharmacopoeial Medicines Compendium. 2013. Available at: http: // mc.usp.org. [Accessed 24 August 2013].

\section{How to cite this article:}

Olorunsola EO, Adedokun MO, Bhatia PG, Tytler BA, Adikwu MU. Optimization of artesunate delivery by formulation in a delayed release prosopis hemicellulose matrix. J App Pharm Sci, 2017; 7 (05): 142-146. 